\title{
Casemix adjustment for outpatient service: a tool for resource allocation of social security population in Thailand Nilawan Upakdee*1, Supasit Pannarunothai ${ }^{2}$, Thaworn Sakunphanit ${ }^{3}$ and Rangsima Preechachard ${ }^{4}$
}

\begin{abstract}
Address: ${ }^{1}$ Faculty of Pharmaceutical Sciences, Naresuan University, Phitsanulok, Thailand and Centre for Health Equity Monitoring, Faculty of Medicine, Naresuan University, Phitsanulok, Thailand, ${ }^{2}$ Centre for Health Equity Monitoring, Faculty of Medicine, Naresuan University, Phitsanulok, Thailand, ${ }^{3}$ National Health Security Office, Nonthaburi, Thailand and ${ }^{4}$ Social Security Office, Nonthaburi, Thailand

Email: Nilawan Upakdee* - nilawanu@nu.ac.th

* Corresponding author
\end{abstract}

from 23rd Patient Classifications Systems International (PCSI) Working Conference

Venice, Italy. 7-10 November 2007

Published: 26 November 2007

BMC Health Services Research 2007, 7(SuppI I):A3 doi:I0.1 186/I472-6963-7-SI-A3

This abstract is available from: http://www.biomedcentral.com/I472-6963/7/SI/A3

(C) 2007 Upakdee et al; licensee BioMed Central Ltd.

\section{Introduction}

Social security scheme (SSS) is a compulsory health insurance scheme covering formal workers in Thailand. The scheme pays health care providers on a flat capitation rate to cover both ambulatory and inpatient care. Capitation payment has caused strong incentive for cost-containment, hence caused under-treatment. To prevent adverse effects, the Social Security Office (SSO) is interested to explore outpatient casemix to complement diagnosis related group.

\section{Objectives}

The aim of this paper was to examine a burden of illness for outpatient care in the SSS population and the application for resources allocation to providers of health services.

\section{Data and method}

A retrospective study was carried out with secondary data of individual electronic database with the application of risk-adjustment method based on Adjusted Clinical Groups (ACGs). Individual data for outpatient services in 2005 were compiled from the SSO. The data contained demographic information with registered hospital, all diagnoses, and annual charge. The end results yield 65 categories of patients and the resource utilisation as annual charges was analysed comparing between public and private registered hospitals.

\section{Results}

About half of the populations had acute minor condition. The differences across two types of health care providers were the number of utilisation and annual charge. Only acute and chronic conditions were selected to examine the pattern of disease, service utilisation, and average annual charge. The results showed the same pattern of disease distribution, while differences in outpatient visit and annual charge were influenced by age and gender.

\section{Conclusion}

The burden of illness in a social security population can be described in terms of ACG casemix using the individual data for outpatient care. The differences between health service utilisation and annual charge between health care sectors were the result of differences of inputs and outputs in the defined populations according to their morbidity patterns. Future policy reorientation should aim towards the development of financing policy on ambulatory services according to health needs identifying by morbidity patterns. 